\title{
The Four Different Aspects of Man-World Relations and the Ontological Nature of Culture
}

\begin{abstract}
Salahaddin Khalilov
Azerbaijan University

In traditional philosophy, man is usually treated as a subject of knowledge, not as a subject of activity. This naturally led to an ignorance of his creative side and had its echoes in the models of the world put forward. Thus, when the world was mentioned the world meant was that perceived by man and the world man created or planned to create himself was given either a secondary treatment or else it was completely forgotten. But, as man is carrier of active spirit, the things he creates have their place in this world along those created by God. It is without doubt that things created by man are not produced against God's will. Still, human creativity is the corruption of the original creation, of the harmony of the world, of the book of nature. Man brings order, so to speak, to the world. He achieves this however at the cost of corrupting the Great Order within some narrow limits. Man himself is among the many highly interesting books written before and there exist as many variations of this book as there are human beings. What is the most difficult for man is though, to read his own book, to understand himself. In this article, the concept of the culture as a human creation is analyzed in the light of Man-World and Man-Nature-God relations. In this case, the author firstly explains the four different world models and then determines the boundaries of science and culture, as well as the individual and social strata of culture.
\end{abstract}

Keywords: culture, ontology, Man-Nature-God, world models, knowledge

\section{Man and World}

First classical philosophical teachings originate together with man conceiving himself as something apart from nature and placing himself against it. Man, seeing nature only in the beginning and struggling to understand it, tries to understand the basic quality that separates him from nature; that is, spirit, and the relation between spirit and nature. The whole sphere of emotions, thoughts, likes, spiritual qualities all fall within the scope of the concepts of spirit and soul. The world is divided into two parts: all things that are material denoted by the concept of nature and those things that are not material; that is, those that we cannot see, touch; by the concepts of spirit or idea. Spirit, as it is either understood as the individual spirit, that is, at the level of individual man, or else as absolute spirit, i.e., God, an approach that takes into consideration the relations between the three sides, rather than those between these two has been developed. For centuries, the problematic of philosophy has been limited to the relation between the sides in question.

This distinction has also been expressed in terms of the distinction between the "Earth" and the "Sky."

Salahaddin Khalilov, professor of philosophy at Azerbaijan University, Head of the "East-West Research Center," Editor-in-Chief of the international journal Felsefe ve Sosial-siyasi Elmler (Philosophy and Social-Political Sciences); main research fields: Philosophy of Science, Science about Science, Philosophical Comparativism, Phenomenology, Philosophical Aspects of Eastern and Western Civilizations, Philosophy of Abu Turkhan, and Cognitive Theory. 
Those that exist in between these have, however, remained outside the sphere of philosophical investigation. It is not a coincidence that in the Koran creatures as a whole is spoken of as: "earth, sky, and those in between" (Al-Anbiya, 16).

According to our opinion, world is conceived as those that exist in between. For, neither absolute spirit, nor absolute matter can be grasped by human understanding. We accept not the poles but what exists in between them and what is, as such, obvious to us and can be grasped through certain means as the real world. In this world, everything expresses a certain contact, synthesis, "cooperation” of the idea with which is material. Man himself is indeed among these. Man is actually the highest concrete exemplification of the cooperation in question. It follows that man is both a material and a spiritual being. Man, however, differs greatly from other beings as to the particular way spirit is embodied in him. Human spirit is active, creative spirit. Man is accordingly a carrier of pure spirit.

But, as man is carrier of active spirit, the things he creates have their place in this world along those created by God. It is without doubt that things created by man are not produced against God's will. Still, human creativity is the corruption of the original creation, of the harmony of the world, of the book of nature. Man brings order, so to speak, to the world. He achieves this however at the cost of corrupting the Great Order within some narrow limits. As Rabindranath Tagore puts it nicely, "Of course our creations are mere variations upon God's great theme of the universe” (Tagore 2007, 370). Yes, the revisions brought by man are small in scale, but we must not forget that a new order established at a local scale brings with it the corruption of an order at the bigger scale. As man is familiar only with some levels of the natural constitution, he cannot take the fine structure that exists at deeper levels into account. Hence, the creativity of man inevitably manifests itself both as the affirmation of a certain idea at the level of macrostructures and as the destruction of thousands of ideas at the level of microstructures. Abu Turkhan expresses this as follows, "White page belongs exclusively to God, what we do is to write upon what has already been written” (K. A. 2012, 41). Actually, man himself is not a white page either. Man himself is among the many highly interesting books written before and there exist as many variations of this book as there are human beings. What is most difficult for man is though, to read his own book, to understand himself.

We must distinguish the mission of human spirit in general and the essence of man in this sense from those qualities that characterize each human spirit singly as opposed to other spirits. These individual spirits are designated by the concept of soul in the philosophical literature. This concept also encompasses the spiritual-moral world of man as a whole. So, not only the faculty of understanding, but also pleasures, emotions, and spiritual-moral qualities are all included therein. These three domains take shape in science, art, and spirituality (i.e., religion and morality) respectively. In the model of the world, man develops Man-Nature-God, however, the devotion of a separate room for the products of his own activity, takes place at the higher levels of the development. Then, one should take human activity as something within the structure of the model of the world understood as a large-scale social reality.

A God, a nature and an image of man in general can be seen as the elements requisite for a proper point of departure in forming a model. The difficulties that the new reality brings with it can result from the fact that a sufficient abstraction has not yet been achieved concerning the individual activities, the combination of these activities into certain groups, inner dynamics of these groups and the relations in between these groups themselves that occur at different areas. 
Philosophy does not deal with particulars. Particular phenomena belong more to history as a field of investigation. The area of particulars accordingly remained for a long time as an area of history and gained a special status; it came to be designated under names like ethnography, historical anthropology, science of culture, etc. Concepts like "culture," "technology," “civilization,” etc., are used in different senses in the works of different authors. Hence, various models are built and scientific explanation of this process has been provided from various points of view. As a result, teachings, branches that, often interfering with and repeating each other, cannot meet on a common ground emerged. The main reason behind all this is that the true nature of the problem is not treated at the philosophical level, that is, that generalized abstract images and characters of these phenomena at the larger scale scientific landscape of the world have not found their proper place.

Manifestations of social progress in horizontal and vertical directions are still confused with each other. Some try to take science and technology as components of culture while others seek criteria to determine the boundaries between civilization and culture. Some prefer to talk of many civilizations while others of a single one. Some try to associate culture, others civilization with religion. In short, in painting the highly rich and multifaceted landscape of the social life, each approaches it from a different angle. Then, which factor should be taken as the general characteristic of it? Is there a single nature behind all this diversity? In other words, are we to take one principle as such a nature or more than one?

All depends on which method of addition is preferred and which items are identified as invariants. What should be noted here is that it is not always through understanding the parts and through adding them that the whole is understood. As is told in an ancient Indian tale, it is not possible to understand what an elephant is like on the whole by collecting the descriptions of blind men each touching a different part of it. Nobody denies the existence of different cultures. But there are attempts at adding them to each other and existing methods are used. That is why my opinion is to propose a new method of addition.

One of the principles of this addition is following: "the sum of the addends is equal to the biggest addend." There were "two," "three," and "six." All added to each other and only "six" remained, two and three disappeared. The implication is this: the biggest culture must take the place of all small cultures. This principle has an affinity with the globalist approach. Here, a process of integration of the world under the influence of the most powerful country is what is at stake. There are, however, alternative approaches to this question. According to the traditional understanding of summation, the sum comprises the addends within itself. But it is also possible that all addends get lost and only the sum remains. This is compatible with the mathematical operation dealing with the addition of numbers. In the place of "two," "three," and "six," there is now only eleven. That, after the addition, each element may preserve its relative independence within the set is also possible. Hence, the total culture is like a matrix, so to speak, elements of which are national cultures. In other words, there were "two," "three," and also "six;" but now there is "two," also "three" and also "six" and there is, in addition to these, "eleven." The possibilities of different ways of addition are not, however, limited to these.

For instance, in the above example, there are four, seven, and nine. They arise from pair wise summation and have been included into the matrix as subsets. In fact, all the alternative variants that each number includes in itself amount to as great a number as its factorial. From a combination of a few basic events come a great number of alternatives. The agreement between various cultures is not their coexistence and presents many possibilities for their combination. The other side of the story, however, is that, among the cultures in question, along with those that grow bigger through complementing, fortifying each other, there are also those that diminish through weakening, opposing each other (similar to the familiar optical phenomena of diffraction and 
interference). It is possible for the sum to be smaller than the addends in this case. The important thing is to make sure that cultures that harmonize with and enrich each other live together. It is wrong to bring together cultures that are not compatible with each other, without a prior phase shift and process of adaptation.

\section{Culture within the Context of "Models of the World"}

In all metaphysical-philosophical teachings, in all religious-philosophical investigations, nature and man are both taken either as self-existent beings or as beings created by God; no special attention is paid to man as a creative being and to his creations.

In traditional philosophy, man is usually treated as the subject of cognition, not as the subject of activity. This naturally led to an ignorance of his creative side and had its echoes in the models of the world put forward. Thus, when the world was mentioned the world meant was that perceived by man and the world man created or planned to create himself was given either a secondary treatment or else it was completely forgotten.

However, the living world has been programmed. And the objects of the non-living world also contain certain information; they have certain forms and structures. These forms are the copies of an idea. The reviving of this copy requires energy from outside. For the reviving of idea, the energy source could be obtained only due to the intellectual potential of man. ${ }^{1}$

From this stand point, I think that the "four world models" can be helpful in determining the place of culture within the cosmogonic system.

"First world" is a world that is composed of the "Ego" and the "non-Ego" and that accordingly has the "ego" as its center. The "non-Ego" is actually the tip of the iceberg. The "first world" is actually distinct for each person. There are then as many "first worlds" as there are men. As these are always individual and incomparable, however, each person sees the whole world through his own world. As a result, "first world" is unique for each person. There is here no place for culture yet. Each person is natural in his own world. The things he produces cannot seem alien or artificial to him and so, they cannot be taken to constitute some alternative to his natural being.

Yet, there is also the "second world." This is the world that is formed out of the addible parts of the "first worlds" and which is as such common to everybody. This world is built upon cognitive trust. The collection of individual sense experiences and of knowledge derived from these experiences is possible on the condition that individuals trust others and experiences of others. That cognitive emotions, logic, and mechanisms of thought are same for everybody, or at least the fact that everyone believes in this sameness, ultimately leads, at the rational level, to accumulation of cognitive data and to gathering together of individual worlds in the form of one big world. I have a certain idea of London through what I read, heard, and what others told me (through movies, etc.) even if I have never been there and I believe in its existence without even being aware of doing so. Moreover, my belief in its existence is in no way less a belief than my belief in the existence of the city I am currently living in. Hence, our ideas about this big world are formed out of the experience of others. And, logos and trust are the unifying factors.

Accordingly the "second world" is, in a manner of speaking, bigger than the "first world." It must not be forgotten, however, that the second world comprises only those aspects of the first that lends itself to rationalization and that are as such communicable to others. The individual-inner aspects of the "first world," impressions, memories, all unconscious life as well as the system of values do not get transferred to the second. 
The "third world" is the world of possibilities. This world, besides the sensible experiences and knowledge of men, attained both individually and through the experience of others, and the big portrait of the world formed out of these, also comprises those things that are produced by imagination or more precisely; the infinite diversity that can only be represented through imagination; the whole system of alternative worlds. One may think "third world" to be actually far from reality and to have a merely imaginary quality. What has a possible being, however, can also exist (or has already existed) in the real world. This is what Hegel meant when he said "the rational is the real" (Hegel 1975, 24). What is questionable here is the extent to which an agreement exists between possibilities and imagination. Sensible experience can only testify to the realized event. But, each time, it is only one among a hundred (in truth; infinite) possibilities that is realized. The existence of a different situation or of a different time and place allows, however, the realization of other possibilities. Hence, even those, which remain unrealized, are the potential realities of this big world. Just as one must take not only kinetic but also the potential energy into consideration in physics, the big model of the world must encompass all the possibilities and indeed all the alternative worlds.

The world of possibilities is infinite. Despite this however, it cannot encompass the individual worlds. This is so insofar as individual world does not simply consist of rationality and it also encompasses those twilight zones that cannot be rationalized and that, as such, remain outside of the sphere of consciousness.

The "fourth world" is an infinity, which encompasses the all first worlds, as well as the second and third worlds, but which exceeds their sum and which extends beyond the possibilities of the human knowledge. The infinity in question includes, besides luminous and twilight ones, dark zones as well. The absolute light and absolute dark which man will never reach are also within the compass of this world. The fourth world is God-centered, not man-centered. Only the limited parts of this infinite and endless world in question are illuminated by the human spirit and individual worlds come to be. The second and third worlds, by contrast, are possible through the rational potential of human spirit. But all of these are subsystems of the "fourth world." Accordingly, one cannot talk of any kind of culture in the "fourth world." As man's creations are limited and finite, they cannot be conceived to constitute an apparent modification in the fine and perfect structure of the "fourth world." As this area is beyond the powers of human understanding, we need not give it further consideration.

In the structure of which world what we call culture is found then? Culture emerges, in our opinion, as a result of the relationships between the first and second worlds.

"First world" finds its own expression more in artistic creativity than in the individual life of the person, in his memories and desires. Music, poetry, painting, etc., consist, accordingly, in attempts at a direct expression of the "first world." Man expresses his own emotional experiences through certain symbolic forms. On the other hand, however, art going beyond being a mere form of self-expression for the person begins to lead a life of its own and becomes an actor that shares the leading role with others. The modes of being of the "Ego" which go beyond the "first world," which are presented to others and which can enter into dialogue with them, that is works of art, take their place among the multiplicity of the "first world," in the firmament of the world of "Egos.” They, however, exist outside of the "Ego;” they are alienated beings with a life of their own. They are not actually beings but rather copies, shadows of being. This is so because they are no more alive and they are, as such, deprived of the possibility of change, development and growth. The work of art can be said to be alive only in the process of its creation, only when it is yet within the world of the "Ego," warmed with human breath, in touch with the infinity of the world of the "Ego." After being externalized, it becomes something fixed, 
unchanging; it is multiplied through reproduction and secures a place in the space in between the individual worlds. When adopted by others (readers, viewers, etc.), however, it is as if conceived again, regains life and interacts with the world of the second "Ego." Products of art are in this sense ways of connection between the "Egos."

The assimilation of the work of art by the second "Egos," the use of the fortune in the inter-egoic firmament is hereafter a phenomenon of culture. As a result, the second "Ego" is no longer nurtured and enriched with its own personal experiences only but also with the products of the creativity of the first "Ego."

We shall give further consideration to the question of the inter-egoic firmament or the cosmic space of the "first world."

The formation process of the common space of the "first worlds" develops in three directions. Common world manifests itself in three different dimensions, in accordance with the three basic forms of human activity: sensing, thinking, and practical activity. We already mentioned fine arts which are the common world of artistic creativity. We tried, secondly, to give consideration to the originality of the world that is shaped through practical knowledge and activity. The third dimension is concerned with man's capacity of understanding and originates from the possibility of expressing its understanding through language. This latter dimension is the one that is given the most extensive treatment in philosophy; indeed it is thought to express the very essence of man himself. Yes, man understands the world, even if partially, and builds his own world thanks to those things he has understood. One transfers his thoughts to others by conveying the thoughts in question to the inter-egoic world through words. These words serve as the basis of verbal talk and written texts.

A cosmos made of logos emerges. This becomes the third dimension of the common world. It is a highly distinctive sphere of its own though. This is so insofar as the knowledge of men is passed on to future generations through collecting them in accordance with certain methods. Hence, principle of cumulativism for cognitions is a valid principle. As a result, quite an extensive world of knowledge different from the individual worlds comes into existence and individuals can expand the scope of their own worlds thanks to it. Above, we called this world the "second world." What distinguishes this world from others is the fact that here collection occurs vertically, not horizontally.

"Second world" is a world that exists outside of man's real experiences, a world that is alienated, dull, rationalized, verbalized, symbolically articulated, and a world that is built through reciprocal agreement of men and which is as such, a world accepted by all, a world that is turned into a common ground. Above, we explained this world. Even though compared to the first world it is pale and monotonous, it is a world that belongs to all of them, and having originated from the operations of rationalization and collection of sensible experience, it is quite an extensive world. It is actually a world that men call world at the level of quotidian consciousness. It is, more precisely, what we call the external world. The "first world," on the other hand, corresponds to the inner world of each individual. However, in the cosmogony offered by us, "first world" is understood to comprise not only the inner world but also the external world shaped through individual-sensible experience.

The shaping of the "second world" is not obtained through the collection of the "first worlds" at the rational dimension. This also includes the rational results of the sensible experiences of earlier men, of older generations. The distinguishing mark of the second world is its being shaped by the power of the rational potential of the whole human history, not only of the presently existing humanity, that is, by the power of not only those alive but also of those who lived before. 
At the level of everyday awareness though, men believe in the reality of the world they are familiar with. It is trust, then, which exists at the foundation of the world. If men do not trust what they read, heard from others their worlds would be so limited that the "second world" could not exceed the boundaries of the first. Our world grows thanks to others.

The minds of individuals taken singly do not suffice for taking all the experiences of others and older generations into consideration and for their storage. The memory of a single person on the other hand, in being beyond the reach of other people, is not a proper medium for collection and common use. Thus, there are ways of storing knowledge. Ways, which make it possible to copy, duplicate and distribute knowledge to everyone interested.

The life of man consists of the processes of reciprocal relation and influence between his world ("first world") and the "second," "third," and "fourth" worlds. Just as, in biology, life is understood to be a process of relation and interaction with the environment, life is itself such a thing taken in its general significance. The individual life of man is in relation with those who exist at the same level with him, that is, with the lives of other individuals and the means through and milieu in which these relations are to occur are taking shapes in space.

Relation with the "second world," in other words, with the world of knowledge and the virtual corporeal world that is equivalent to it, allows the individual to feel himself to exist in a bigger place as well as to interact with this bigger place. This is the rational aspect of life.

Empirical knowledge derived from the senses and the general knowledge deductively obtained from them is collected in the "second world." However, pure reason has no doubt a role itself in the ordering of this world and this is possible on the basis of a reciprocal relation with the third world.

The reciprocal relation with the third world becomes possible through imagination and creative thinking. As deductive thinking does not have an empirical basis, that is, as it does not depend on history, not only what has already happened but the whole range of possibilities becomes a virtual reality. As not actualities but possibilities are learned in the world in question, the determination of those that are to have a reciprocal relation with the "first world" is prominent. The world in question is then the world of philosophy. The reciprocal relation and influence between the first and third worlds is a process of life or philosophical creativity.

The fourth world, as it can be reached only by belief or faith, not by knowledge, the relation and interaction of the "fourth world" with the first may seem to consist in religious experience. The effort on the part of man to reach the "fourth world" through the third can be understood, more fittingly, to be an attempt, in a sense, at the clarification of the religious-philosophical experience through philosophical terminology.

Which ways of connection are used in the reciprocal relation between the third and fourth worlds? In other words, is it possible to talk of philosophical or religious culture?

As we explained above, culture is fundamentally a means of connection, a common space that exists in between the parties of the "first world" and which serves as such to relate the first worlds with each other and the "first world" with the "second world." As a result, if the space in between is empty when individuals want to communicate with each other, mutual understanding will be impossible. Nobody can welcome another into his inner world. Parties make use of the transition area, its common language established for dialogue. Culture is necessary so that individual can join the society. One cannot speak of an independent culture of an individual but only that of some society; some social group. 


\section{Science and Culture}

We cannot conceive the boundaries of neither science nor culture if we do not know what belongs to man, what to society, and what to humanity. Due to the failure of a precise demarcation between their natures, many cannot draw the line between science and culture and even take science itself as one of the components of culture. Oswald Spengler said, “... What culture is, what its relations are to visible history, to life, to soul, to nature, to intellect, what the forms of its manifestation are and how far these forms-peoples, tongues inclusive of everything known, but in a picture of life, and presents them not as things-become, but as things-becoming” (Spengler 1927, 5-6).

We need to distinguish in every field of activity between the levels of the hierarchy that goes from mere quotidian consciousness to full blown scientific theorizing through a proper classification of these fields themselves. We shall consider the difference, for instance, between the practical and theoretical sides of economics, between the art of the physician and science of medicine, or between teaching and pedagogy as vertical differences of degree. Even in the very same field, its praxis and theory constitute different levels. At which level then culture emerges? Does it make its appearance in the practical activity of man or else in the scientific knowledge of the activity in question, that is, at the scientific-theoretical level? Unfortunately, cultural scientists generally fail to take the vertical classification into account and the classification according to the field gets confused with that according to the level.

If we contrast culture only with nature and consider everything that is unnatural, everything that is produced as something falling under the scope of culture, we thereby "enrich" the content of culture with elements that do not belong to it. Many things produced by man, on the other hand, do more belong to the level of creativity than to culture.

Culture does not involve creativity. It is not a way of man's self-expression, of expressing his own world and both the activity of individual creativity itself and its products fall outside the sphere of culture in this sense. Culture comes into existence solely in the process of socialization of the individual. As such, it belongs not to the individual worlds but to the common space in between them. In other words, culture is not man's self-expression but rather the assimilation of this self-expression by others; hence, it consists of those things this self-expression creates for everybody.

If we distinguish between the concepts of "I" and "we," culture is that which is related to "we," not to "I."

In this sense, no creative activity, being it scientific, artistic, or philosophical, can be considered to belong to the scope of culture. This is because, these are wholly subjective and original products and they are meant for a selected few and as such do not descend to the level of the understanding of the masses. What, then, explains the process by which science turns into a cultural phenomenon? The answer, which goes without saying, is the practical applicability of scientific theories. For instance, that such theories become parts of our lives in the form of technology means that science has thereby become a cultural phenomenon. A washing machine is offered for the use of everyone and no expertise is needed to use it.

\section{Culture: Individual and Social Strata}

Individual and man (or rather the concept of man) are different things. When we talk of man, we usually take his history to begin with the day of his birth. Accordingly, his genetic heritage, his social milieu, and the states and situations, which he lives in as a result of the struggle between the milieu and the heritage, are 
privileged. We shall pay heed to the fact that the life of man is a continuation of the life of previous generations and that it is as such shaped as a part of a larger and longer process. Social milieu and human world as a whole is the product of the activity of earlier generations, not of a single person. The life of man is in this sense a matter of dialogue with previous generations. More precisely, there is dialogue, relation and interaction of man with people around him, that is, people that he shares his milieu with, as well as with those earlier generations that have already shaped this very milieu. Taken in a sufficiently large scale, this milieu encompasses both present humanity and all earlier generations. Taken more concretely, however, it is enough to take those factors that have direct influence in the formation of the local milieu in question.

Man can never be said to an individual in this sense. For, man's life consists, from the very moment of birth, of the system of reciprocal relations with others. Culture manifests itself in a milieu, which is shaped through the activities of earlier generations. Thus, for each individual, environment is already a "cultivated" one; it is not a mere natural environment. Likewise, a total rejection of all that is achieved by earlier generations is needed if an individual of a certain age is to return back to her completely natural condition. The majority aforementioned achievements have an influence on the individual well before she has reached the age of self-awareness. What determines the nature of modern man is no longer nature but the cultural milieu in which he finds himself. Each individual life is a continuation of the life of all previous men.

We do not pretend to an unconditional use of the model we offered. Socio-cultural milieus differ greatly and individuals born into these different milieus live, so to speak, the life of different ancestors. What we want to emphasize, however, is this: Culture is not a phenomenon that extends solely in spatial dimension and that establishes itself in a certain place, but it is also something that exists in time and something that develops continually. Each culture has its own past, present, and future. This temporal axis is wider than the life of any single man.

It is not therefore possible to expose the meaning of culture through a single person, through the processes of reciprocal interaction of a single person with his own socio-cultural milieu.

The transmission of knowledge as mere knowledge and its materialization through symbols for the purposes of such a transmission is one thing, the application of knowledge in the practical domain and its being stored in its synthetic unity with nature, with matter, that is, in the form of something transferred to the material medium is another. What is usually meant by material culture is the materialization, realization of man's thoughts, of his acquired knowledge, and of the projects he forms on the basis of his knowledge. Men, however, apply their knowledge and projects not only to nature but also to society, to the social milieu. Hence, new systems, mechanisms built on the social raw material, new social structures, networks, etc., are all products of human thought. These, however, belong to society, not the "second nature." Here, we allow ourselves to use the concept of second nature for purposes of symmetrical treatment of the subject. The social milieu that is established without any subjective intervention on the part of the individual can be seen, so to speak, as the first society. The intervention of the individual, the transfer of his thoughts to the social raw material, and their realization can result in the emergence of a new social reality and it is more apt to call this new social being a "second society" in opposition to the first one.

To talk of symmetry is still difficult though. For, while second nature is the product of the creativity not of one person but of whole humanity, in the option we presented the "second society" forms either through the individual effort of a person or through the collective effort of his contemporaries, second society itself is, accordingly, a cultural phenomenon built by people; by previous generations. 
Actually, further differentiation in the phenomenon we called "second nature," itself is necessary. For, the material culture created by previous generations is not merely adopted by the new generation. This new generation participates itself in this process of creativity and makes additions and changes to the material reality, to the material medium. These changes can be quite substantial in some situations. For this reason, we have to distinguish between the "second nature" whose subject is all generations and the new culture whose subject is the new generation (our contemporaries) and which emerges only in relation to us as the material realization of our intellect. For, this is wholly a new phenomenon. It is new because structures that are products of the rational activity of someone are not yet something that the masses can understand. Masses have not yet assimilated the rules of its use, nor its purpose. A process of its assimilation is required before a technological innovation can turn into a cultural phenomenon. The rules, technique, methods, etc., of this process occur in front of our eyes and with our active participation. The system of education, information technologies, and mass media all participate in this process. We become participants in this process of shaping. These innovations usually prove inaccessible for earlier generations (for those that are alive). The new generation, by contrast, grows up with this new culture and it becomes the face of culture now which influences its own carriers and causes a change in the very way of thinking itself.

The way of thinking, the way of life, social norms etc., are directly passed on to us by our parents and teachers. We thereby assimilate the previous material culture and the corresponding spiritual culture as the heirs of the previous generation. This culture, however, conflicts with the newly emerging culture and the new spiritual culture that goes with it. As a result, an opposition is appeared between the modernism of the new culture and the conservatism in education.

\section{Notes}

1. For detailed information see Salahaddin Khalilov, Phenomenology of Life or Life of Idea, Baku: Azerbaijan University Press, 2012, 27.

\section{Works Cited}

Al-Anbiya. Surah The Prophets Verse-16.

Hegel. Werke 7: Grundlinien der Philosophie des Rechts. Frankfurt am Main: Suhrkamp Verlag, 1975.

Khalilov, Salahaddin. Phenomenology of Life or Life of Idea. Baku: Azerbaijan University Press, 2012.

Kniga Aforizmov: Izbrannoe iz Izbrannix. Sost. S.Khalilov. (Book of Aphorisms: Selected from the Selected). Moskva: Alfa-M, 2012. Cited as K.A.

Spengler, Oswald. The Decline of the West: Form and Actuality. Trans. Charles Francis Atkinson. New York: Alfred A. Knopf, 1927.

Tagore, Rabindranath. "Personality.” The English Writings of Tagore: Essays, Vol. 4. Introduction by Mohit K. Ray. New Delhi: Atlantic, 2007. 